\begin{tabular}{c} 
International Journal of Engineering \& Technology, $7(2.28)(2018) 386-389$ \\
International Journal of Engineering \& Technology \\
SPC \\
Website: www.sciencepubco.com/index.php/IJET \\
Research paper \\
\hline
\end{tabular}

\title{
Modeling principles of the digital infrastructure of it services in sustainable low carbon transport systems
}

\author{
Trofimenko Yu. V. ${ }^{1}$ *, Nekrasov A. G ${ }^{\cdot 1}$, Sinitsyna A. S ${ }^{.2}$ Atyev K. I. ${ }^{1}$ \\ ${ }^{I}$ Moscow Automobile and Road Construction State Technical University (MADI), Moscow, Russia \\ ${ }^{2}$ Federal State Institution of Higher Education «Russian University of Transport» (RUT - MIIT), Moscow, Russia \\ *Corresponding author E-mail: ywtrofimenko@mail.ru
}

\begin{abstract}
The principles of adaptive management of sustainable low carbon transport systems (SCTS) are developed based on the interaction of intellectual and Internet technologies, which ensure the effectiveness of core elements of the system throughout the life cycle of digital infrastructure and IT services. The technologies of proactive (anticipatory) management are accompanied by targeted procedures for reconfiguring the structures of transport system, and provide a comprehensive forecast of the system's behavior and increase its efficiency on the basis of a large array of digital data. The 4D model of SCTS transformation into the digital environment is developed, which allows integrate the most important modules of the transport system, ensuring highly efficient interaction of various objects in the interest of customers.
\end{abstract}

Keywords: Adaptive Management; Architecture; Digital Infrastructure; IT Service; Lifecycle; Low Carbon Transport System.

\section{Introduction}

The main trends in the development of transport systems (TS) [1 3] are their digitalization, substitution of traditional non-renewable energy sources for alternative low-carbon sources, unmanned drive. At the same time, distributed databases, glossaries, standards, information and communication technologies and low-carbon vehicles form the basis of the system transformation for transferring the transport infrastructure and the transportation process to digital form and provide stability and customer focus at more efficient level [4], [5].

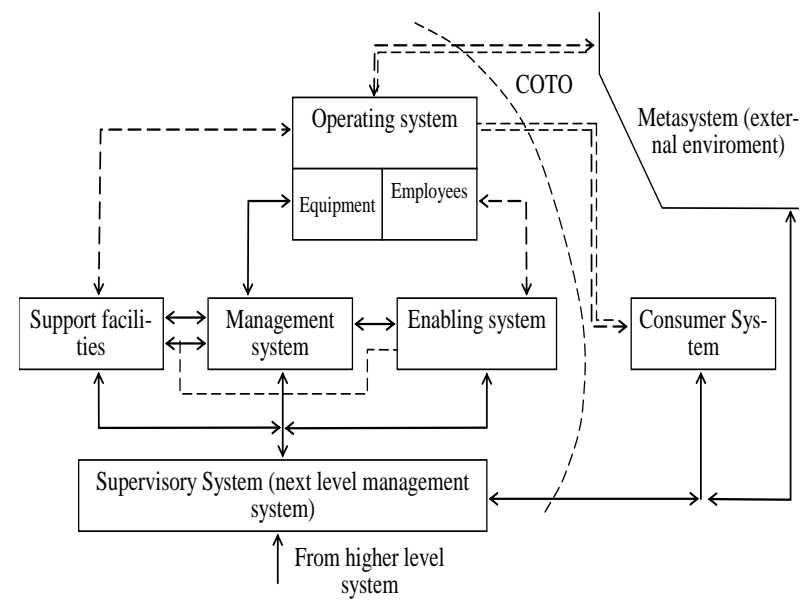

Fig. 1: An Example of a Typical Structure of the Socio-Natural and Organizational-Technical SCTS Object [10]

As a result, a stable low-carbon transport system can be formed (SCTS), which is a socio-natural and organizational-technical object (Figure 1), for the management of which it is necessary to use adaptive cyber-physical systems (Cyber-Physical Systems CPS), through the Internet of things technologies (Internet of Things - IoT) [6 - 10] (Figure 2), automatic identification services, data collection, computer interaction etc., which provide continuous information exchange between CPS elements.

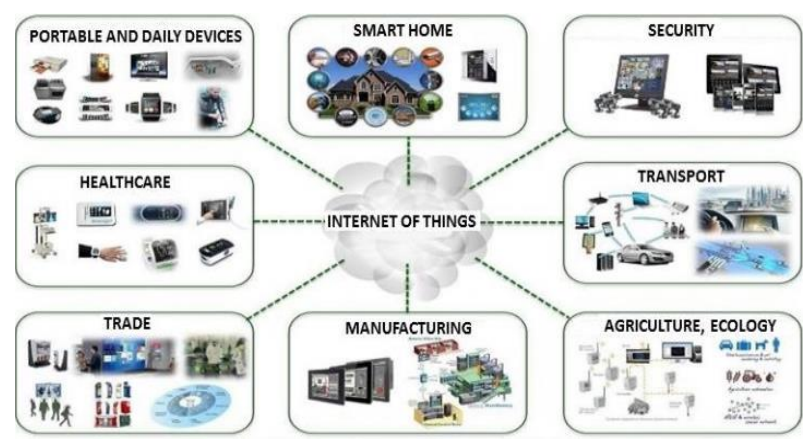

Fig. 2: Scope of Cyber-Physical Systems (CPS) [11]

The key problem is the formation of algorithms for managing the self-organization of the SCTS, as the most effective way to overcome the uncertainty (risks) of the external environment, to maintain structures and functions in new lifecycle management models through adaptive proactive management systems $[12,13]$.

\section{The principles of adaptive management of SCTS and modeling of the digital infrastruc- ture based on the adaptation mechanism}

In the design, implementation and operation of adaptive and selforganizing IT systems of SCTS an important issue is the formal description of these systems and the development of mathematical models of their functioning at various stages of the life cycle. The 
questions of conformity of methods, algorithms and modeling methods of this class of systems with ensuring their autonomous functioning and interaction with each other and with the surrounding eco-environment (ecosystem) become especially relevant.

These circumstances require a revision of the traditional approaches to the modeling of management systems, when the proactivity of these systems (ability to self-control, self-recovery, self-defense, self-configuration and self-optimization) was not taken into account when making calculations and developing solutions to protect and prevent incidents in the ecosystem [14].

For the effective implementation of the intelligent adaptive mechanism of SCTS management at different stages of the life cycle, it is necessary to use the technology of virtualization of digital data and intellectualization of managing transport and logistics processes.

The model of a system with adaptive behavior is a certain mapping of the set of input data on multiple outputs that control the behavior of the system. At the same time, learning, behavior adaptability is usually provided by determined algorithms that change the display function.

One of the trends is the emergence and development in the Internet and intranet environment of the integration processes not only of transport and technology, but also of their interaction with the sphere of digital production. This, undoubtedly, leads to a change in the principles of modeling SCTS.

It is also necessary to take into account the trend associated with setting and solving the problem of multicriteria estimation and analysis of the contribution of Information and Communication Technologies to transport activities, including an assessment of the economic efficiency of SCTS at various stages of the life cycle. This is based on such classic performance indicators used on the computer services market as indicator of return on investment (ROI), quality of service (QoS).

The target orientation of the new concept of proactive management is aimed at ensuring management decision-making throughout the life cycle of the SCTS, which will function according to the following scheme based on digital data:

Data $\rightarrow$ Information $\rightarrow$ Knowledge $\rightarrow$ Decision $\rightarrow$ Action $\rightarrow$ Data At present, brand new components of intellectual information technologies (IIT) have been formed and are actively developing, promising to solve the problem of including formal apparatus of traditional mathematics (computational algebra, set theory etc.) into them. These IITs are based on the non-algorithmic process of managing large data, providing a comprehensive evaluation and forecasting the development of the system.

Developed architectures are focused on services and based on the concept of virtualization of its components through their digitalization create a systemic basis for the synthesis of fundamentally new approaches in the management of SCTS, which in their properties will approximate the properties of living organisms. In the work [15], it was shown how it is possible to construct an original fivelevel model of a viable system, based on the neurophysiological interpretation of the functioning of the central nervous system of man In this model, mechanisms of hierarchical and network management are combined, which provides a compromise between centralization and decentralization of the goals, functions, tasks and operations performed in the organization. This model has found application and use in the solution of various classes of scientific and technical problems of ways of transformation of life cycle processes of systems, including the sphere of inter-industry interaction and multimodal transport [1].

Prospects for the development of technologies of this approach in the digital economy (digital transport) are related to the evolution of the transformation from adaptive to creative principles and management methods, from adaptation to the external environment to its proactive formation.

\section{IT-service architecture}

The general pattern of projects on the digital infrastructure of SCTS provides specific customer focus and the wide use of information, large data, the individual characteristics of a particular consumer at the specific time and place, the application of the technologies and principles of digital transformation of real business processes [17, 18]. Digital transformation is systemic in nature, and involves the solution of complex cultural, social and organizational-technical problems.

To increase the productivity of IT service and increase the value of IT service, the authors developed brand new 4D-model for the transformation of SCTS in digital environment.

The transport system is seen as responsive to the wishes and requirements of customers. Therefore, the client's interests are located at the center of such a model (Figure 3).

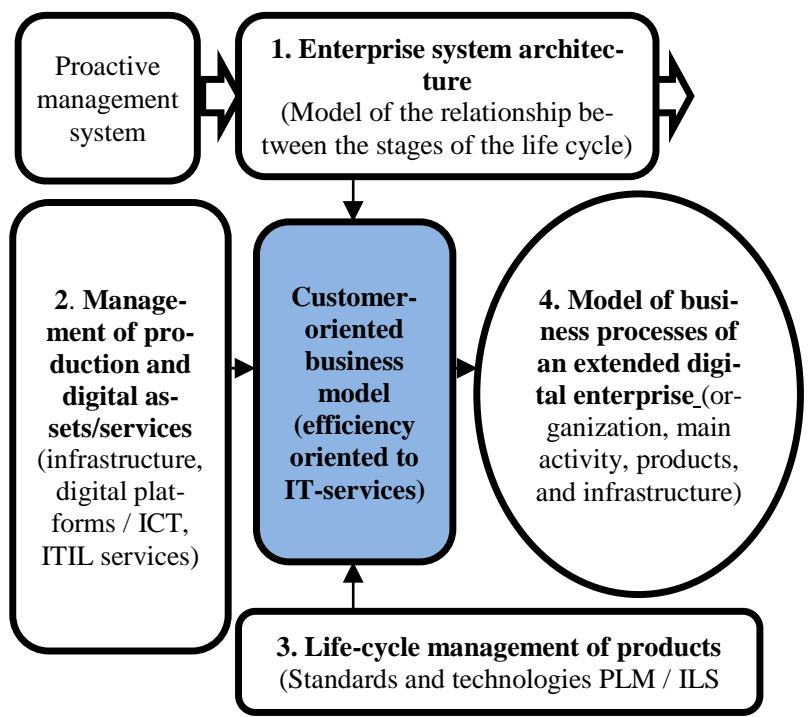

Fig. 3: Scheme of fourD-Model Transformation of SCTS (Enterprise) Into the Digital Environment

This scheme of organization and management is adaptive, and the principles and technologies are called "organic", "natural" (Organic IT) [18], [19].

The construction of the 4D model is based on the hypothesis that the stable functioning (change of state) of the low-carbon transport system is achieved by controlling the interaction of integrated transport and logistics processes (ITLP) and functionally stable information systems (FSIS) at various stages of the life cycle of the SCTS. At the same time, the methodological approach of St. Petersburg institute of informatics and automation of RAS is used, according to which the various subsystems of the SCTS can be in different states depending from the point of view of the life cycle. Charts of variants of structural dynamics (Table 1, Figure 4) reflect different states and types of SCTS structures.

Types of structures - correspond to the transformed elements of the developed 4D model, which assumes the description of not individual subsystems, but the whole state of the whole object, i.e. SCTS. The graphical interpretation of the problem of structural and functional synthesis of the ITLP and FSIS shape is reduced to the search for such a multistructural macro state $S_{\delta}^{*} \in\left\{\mathrm{S} 1, \mathrm{~S} 2, S_{K_{\Delta}}\right\}$. 


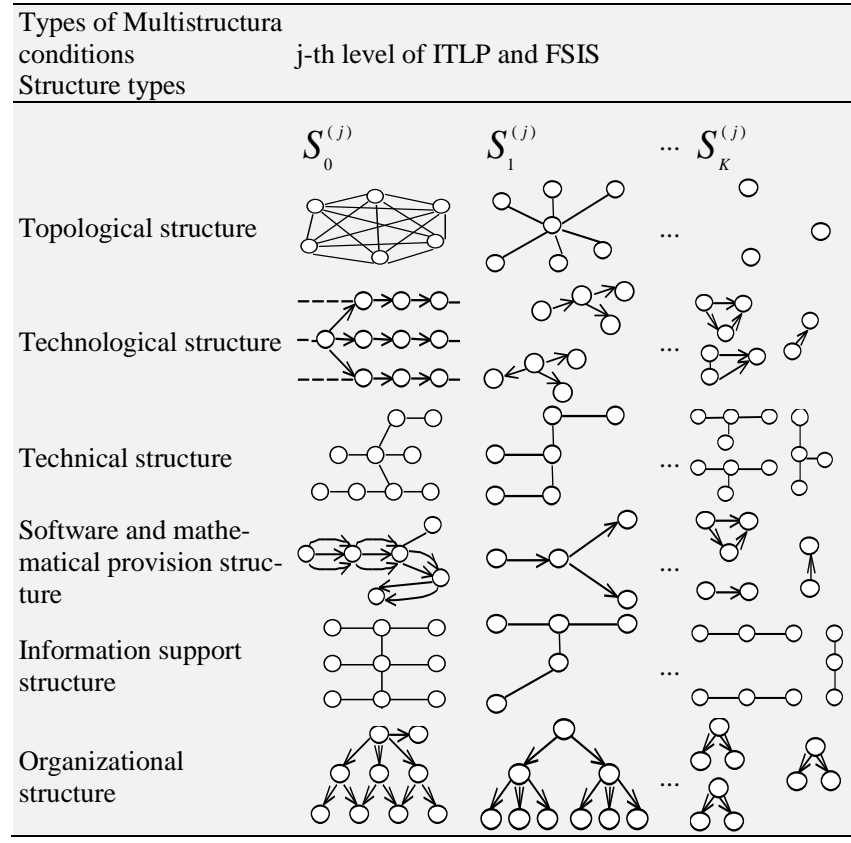

And such a sequence (composition) of performing the mapping operations of the form (6) in time $\prod_{<\delta_{1}, \delta_{2}>}^{t_{1}} \mathrm{o} \prod_{<\delta_{2}, \delta_{3}>}^{t_{2}} \mathrm{o} \prod_{<\delta^{\prime}, \delta>}^{t_{f}}$, with which the optimal program is selected (from the point of view of the generalized efficiency index) for the creation, implementation, operation and development of ITLP and FSIS that ensure their transition from a given (initial) multi-state macro state to a synthesized multistructural state, with the help of which, precisely, the required shape of the systems under consideration is specified. This class of problems can be considered as a subclass of managing problems of the structural dynamics of ITLP and FSIS.

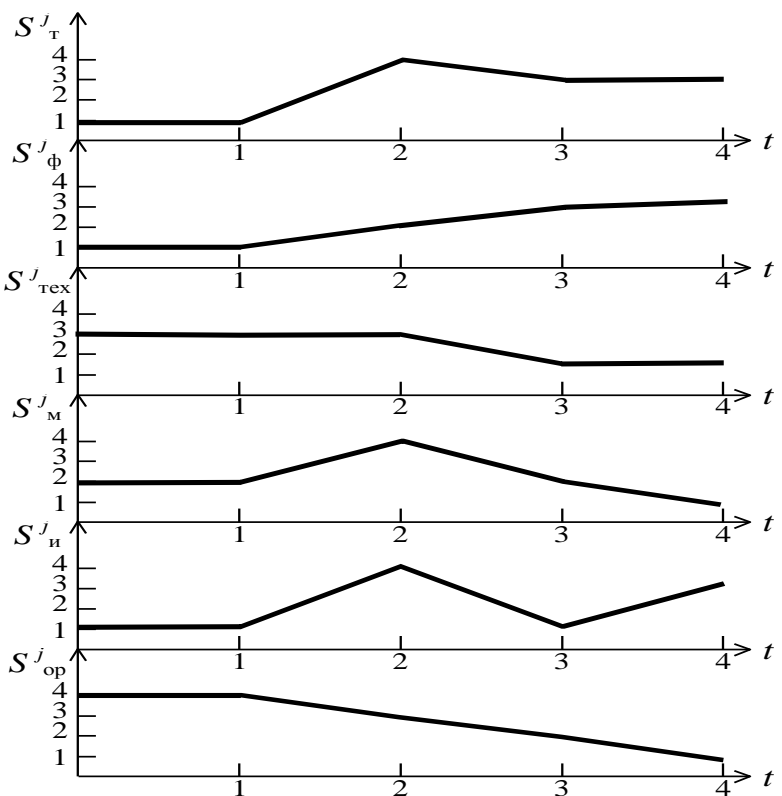

Fig. 4: Charts of Changes in the Structural States of ITLP and FSIS.

Along with the graphic interpretation of the problem under study, the following set-theoretical description can also be proposed: it is necessary to develop principles, approaches, models, methods, algorithms that allow to find such $\left\langle U_{*}^{t}, S_{\delta}^{* t_{f}}\right\rangle$, under which the following conditions are satisfied

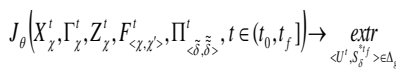

$$
\begin{gathered}
\Delta_{g}=\left\{<U^{t}, S_{\delta}^{t_{f}}>\mid R_{\beta}\left(X_{\chi}^{t}, \Gamma_{\chi}^{t}, Z_{\chi}^{t}, F_{<\chi, \chi^{\prime}>}^{t}, \Pi_{<\bar{\delta}, \bar{\delta}>}^{t}\right) \leq \tilde{R}_{g} ; U^{t}=\right. \\
\left.\Pi_{<\delta_{1}, \delta_{2}>}^{t_{1}} o \Pi_{<\delta_{2}, \delta_{3}>}^{t_{2}} o \Pi_{<\widetilde{\delta}, \delta>}^{t_{2}} ; \beta \in B\right\}
\end{gathered}
$$

where $\mathrm{U}^{\mathrm{t}}$ - control actions allowing to synthesize both the structure of the ITLP and FSIS systems and the processes of their functioning; $\mathbf{J}_{\theta}$ - cost, time, resource indicators, characterizing the quality of functioning of the systems under consideration (ITLP and FSIS); $\mathrm{q} \in \mathrm{Q}=\{1, \ldots, 1\}-$ set of index numbers; $\Delta_{g}$ - variety of dynamic alternatives (variety of structures and parameters of the ITLP and FSIS, variety of programs for their creation, implementation, operation and development); B - number variety of space and time, socio-economic, technical and technological restrictions taken into account as a synthesis of parameters, structures and laws governing the ITLP and FSIS; $\tilde{R}_{g}$ - set of values; $T=\left(t_{0}, t_{f}\right)-$ is the time interval at which the parameters, structures and laws governing the ITLP and FSIS are synthesized.

In our opinion, a mathematical description of this model is necessary for the formation of new adaptive systems in the digital economy. This proposal we address to the professional mathematical community.

Currently it is supported only by standards and requirements fixed in them and models and is represented by the interaction of 4 modules: the system architecture of SCTS; management of industrial, digital assets and services; product life cycle management/PLM; business processes of transport activity. System integration of information infrastructure, digital data and IT services, organizational structures, products (transport work) is realized within the framework of an integrated customer focused transport system, using the principles of adaptation of the interaction of its elements in the life cycle process (according to the Rubik's Cube principle).

Modules contain data on various elements (products, assets, services) at different stages of the life cycle of a single digital infrastructure and business system. The cells in the modules are represented by the classification and description of entities (objects) of the SCTS. The functioning of the 4D-model is supported by the requirements and consistent description of particular models of elements, reflected in the PLM standards, the integration of technological processes, business processes, the architecture of the SCTS based on the life cycle of the integrated system.

The evolution of the relationship between SCTS and consumers is aimed at revolutionizing the expectations of new goods and services. Therefore, the transport system providing the delivery of goods must be fast, accessible and effective for the customer.

High-speed transportation of goods puts new requirements and models for the process of ensuring the efficiency and sustainability of transport-technological processes, IT-service system (ITS) in the interests of end customers. To do this, it is necessary to develop high-speed transport and logistics technologies and apply the methods of logistics engineering which allow to provide digital IT services to customers to ensure profitability in conditions of volatility in the market environment [20 - 22].

\section{Conclusion}

Systemic transformation of transport activity should be carried out mainly on the basis of modeling complex socio-natural organizational and technical systems on the principles of adaptation and integration of system elements to overcome the problems of uncertainty and functioning in conditions of breakdowns.

The principles of adaptive management of sustainable low carbon transport systems (SCTS) are developed based on the interaction of intellectual and Internet technologies, which ensure the effectiveness of basic elements of the system throughout the life cycle of digital infrastructure and IT services.

The technologies of proactive (anticipatory) management are accompanied by targeted procedures for reconfiguring the structures of transport system, and provide a comprehensive forecast of the system's behavior and increase its efficiency on the basis of a large 
array of digital data. The 4D model of SCTS transformation into the digital environment is developed, which allows integrate the most important modules of the transport system, ensuring highly efficient interaction of various objects in the interest of customers.

Technologies of proactive management of SCTS are promising for multi-structure systems (transport and logistics facilities), due to which objects in the prevailing (projected) environment can perform the tasks with the required degree of stability.

\section{References}

[1] Mirotin L.B., Nekrasov A.G., Gudkov V.A., 2013. Increase in the efficiency of freight transportations on the basis of the creation of a stable transport-logistical system of a modular type for high-speed handling and delivery of goods, Moscow: Tehpoligratsentr, pp: 232.

[2] Nikolaoshin V.M, Zudilin N.A, Sinitsyna A.S., 2011. Service in transport: training. Allowance for stud. Institutions of higher education. Prof. Education. - 4 th. ed., Moscow: The publishing center «Academy», pp: 304.

[3] Transport Strategy of the Russian Federation for the period until 2030, approved by the Government of the Russian Federation of November 22, 2008 N 1734-r, as amended. Order of the Government of the Russian Federation No. 1032-r of 11.06.2014. Date Views 03.03.2017. http://rosavtodor.ru/documents/119

[4] Eliseev S.Yu., Nikolashin V.M., Sinitsyna A.S., 2013. Logistic management of freight transport and terminal-warehouse activities: a textbook, Moscow: FGBOU «Educational and Methodological Center for Education in Railway Transport», pp: 428

[5] Nekrasov A.G., Sinitsyna A.S., 2016. Logistic engineering as a tool for integrating logistics systems. Journal Logistics, 12: 40-45.

[6] Kupriyanovsky V.P., Kupriyanovskaya Yu.V., Sinyagov S.A., Dobrynin A.P., Chernykh K.Yu. 2016. Digital economy - various ways to the effective application of technology (BIM, PLM, CAD, IOT, Smart City, BIG DATA and others). Journal International Journal of Open Information Technologies, Vol. 4, 1: 4-12.

[7] Kupriyanovsky V.P., Namiot D.E., Drozhzhinov V.I. Kupriyanovskaya Yu.V., Ivanov M.O. 2016. Internet Things in industrial enterprises. International Journal of Open Information Technologies,Vol. 4, 12: 69-78.

[8] Kupriyanovsky V.P., Namiot D.E., Sinyagov S.A. 2016. Cyberphysical systems as the basis of the digital economy. International Journal of Open Information Technologies. Vol. 4, 2: 19-25.

[9] INDUSTRIE 4.0 - smart production of the future (State Hi Tech Strategy 2020, Germany). Date Views 06.02.2018. http://json.tv/tech_trend_find/industrie-40-umnoe-proizvodstvo-buduschego-gosudarstvennaya-hi-tech-strategiya-2020-germaniya20160227025801

[10] Sokolov B.V., Ptushkin A.I. 2010. Analytical review «The state of research on the problem of managing the life cycle of artificially created objects». Grant of the RFBR №09-07-11004-ano. SPb.: SPIIRAN. pp: 56.

[11] In Chalcis, the program «smart city» starts. - Date Views 03.03.2017. https://1 gr.tv/poslednie-novosti/novosti-grecii/category/v-halkidestartuet-programma-umnyiy-gorod/

[12] Sokolov B.V., Nekrasov A.G., Mirotin L.B. 2011. Development and implementation of methodology and techniques for joint multi-criteria synthesis and adaptive management of the creation, application and development of functionally stable integrated transport-logistics and information systems of a new generation. Journal Vestnik transporta, 6: 25-30.

[13] Okhtilev M.Yu., Sokolov B.V., Yusupov R.M. 2006. Intellectua technologies for monitoring and managing the structural dynamics of complex technical objects. Moscow: Science. pp: 410.

[14] Sokolov B.V., Yusupov R.M., 2008. Neo-cybernetics-opportunities and prospects for development. Report at the general plenary session of the fifth scientific conference «Management and Information Technologies» (UIT-2008). Russia. - St. Petersburg. pp10.

[15] Bir S., 2007. Brain firm. Moscow: URSS. pp: 350.

[16] Kupriyanovsky V.P., Dobrynin A.P., Sinyagov S.A., Namiot D.E. 2017. A holistic model of transformation in the digital economy how to become digital leaders. Journal International Journal of Open Information Technologies, ISSN: 2307-8162. vol.5, p.1: 26-33.

[17] Nekrasov A.G., Sinitsyna A.S., 2017. Transformation of integrated transport and logistics systems into the digital industry. Journal Logistics. Eight: $36-41$.

[18] Vont R., Pering E., Tennenhau D., 2003. Adaptive and proactive computer systems. Journal Open Systems. 7: 4-9.
[19] Yusupov R.M., Sokolov B.V., 2006. Problems of the development of cybernetics and computer science at the present stage. SPb.: Publishing House of SPbSPU, pp. 6-21.

[20] IT service management. Introduction. itSMF., 2003, pp: 227.

[21] Nekrasov A.G., Ataev K.I., Nekrasova M.A., 2011. Managing the processes of security and risk in supply chains: educational-methodical. Allowance. Moscow: Publishing house «Tehpoligratsentr», pp 120.

[22] Trofimenko Yu.V., Nekrasov A.G., 2016. Methodological issues of Ensuring Operational Sustainability and Logistics Systems. Science Journal of Transportation. ISSN 2410-9088. Especial lssue No. 07 International cooperation Journals MADI-SWJTU-UTC. MoscowChengdu-Hanoi. pp: 23-28. 